\title{
What SENIORS HaVe To SAY ABOUT THEIR ENGAGEMENT
}

\author{
Sylvie Doré \\ École de technologie supérieure \\ sylvie.dore@etsmtl.ca
}

\begin{abstract}
The goal of this pre-study was to prescribe a solution to a perceived decrease in student engagement in an elective course on additive manufacturing. The objectives were to:

- identify in what activities the students are engaging;

- identify causes for lack of engagement in their studies, if any;

- identify possible changes to the additive manufacturing course.

A mixed (quantitative and qualitative) triangulation interpretivist approach was used to address the first two objectives. Approximately half (1/2) the students stated that their studies was not their priority, two thirds (2/3) reported that they attended university primarily to earn a diploma rather than to learn and again two thirds (2/3) said that they had difficulty concentrating, signs that most students are not fully engaged in learning. The qualitative analysis provided insight and nuance to the quantitative analysis. It made it possible to identify sources for lack of engagement. Apart from the presence of electronic devices which distract attention, teaching methods, course content and evaluation modalities were often cited. Based on the findings, three changes are suggested to the course.
\end{abstract}

Keywords: student engagement, sources of nonengagement, student perspective, student priorities, behavioral, emotional, cognitive dimensions

\section{INTRODUCTION}

In the mid 1990's, the author developed an elective course on additive manufacturing at École de technologie supérieure (ÉTS). She taught the course on at least eight (8) occasions before becoming of Dean of (undergraduate and graduate) studies from 2003 to 2011, during which period she did not teach. She reintegrated her professorial duties in 2011. After twice teaching an updated version of the same additive manufacturing course (summer 2011 and winter 2012), she was taken aback by the lack of student responsiveness and the decrease in student satisfaction with the course, as measured by official course evaluations, compared to previous evaluations.
She shared her thoughts with her colleagues in the Mechanical Engineering Department through informal discussions. Lack of student attendance, lack of involvement, minimum student effort were common grievances.

Literature reports growing concern of teaching staff and administrators with what is perceived as a decrease in student engagement [8], [9]. Collectively, we seemed to be experiencing the same problem with senior student. The emphasis is placed on seniors because the phenomenon is much more strongly felt with this student population when compared to $1^{\text {st }}$ year students. On a more personal level, the author was experiencing a reciprocal effect [10]: her own pleasure and engagement in teaching this student population was starting to fade, which prompted her to take action.

Engagement is a complex, multidimensional construct and no one definition has emerged from the literature. For the purpose of this study, the following definition was adopted: "Student engagement refers to the student's active participation in academic activities[...], and commitment to educational goals and learning. Engaged students find learning meaningful, and are invested in their learning and future. It is a muldimensional construct that consists of behavioral (including academic), cognitive and affective subtypes. Student engagement drives learning and requires energy and effort[...]. (Adapted from [3], p. 816) from which participation in co-curricular of school related activities was removed).

Most authors propose between two and four dimensions as reported by Appleton, Christenson and Furlong [1]. The proposed definition embraces three dimensions: behavioral, cognitive and affective as proposed by Fredricks, Blumenfeld and Paris [7] which draw respectively on the ideas of participation, investment and positive or negative reactions. Many terms have been used to describe the absence of engagement. Skinner and Pitzer (2015) [10] use disaffection or "burn-out", while Krause [8] proposes inertia which is suggestive of doing nothing. Trowler [11] reports the use of the word alienation by Mann but uses the terms non-engagement, which conveys the same sense of "doing nothing" proposed by Krause; Trowler also proposes negative engagement, which is much more active, but in a negative sense. To illustrate, Trowler suggests attending lectures, 
skipping lectures without excuse and disrupting lectures as examples of positive engagement, non-engagement and negative engagement for the behavioral dimension.

Krause proposes two other meaning for the word engagement. The first takes into account the lifestyle of Y Generation and of previous generations going back to school: university becomes another appointment in an already busy schedule. The second meaning refers to students at risk which engage in academic pursuit as they would in combat or a conflict.

This pre-study is rooted in design science research whose purpose is to "solve problems and construct artifacts", to "develop and design solutions to improve existing systems, solve problems, or even create new artifacts that contribute to better human performance, whether in society or in organizations" ([5], p. 56). It is prescriptive in nature. It is considered a pre-study because it was conducted in only one classroom which might not be representative of the whole senior population. Furthermore, possible solutions have not been implemented nor validated, steps required to complete the study.

As with any design problem, the first step in any design science research project if to understand the problem. To do so, it relies on a mixed (quantitative and qualitative) triangulation interpretivist approach [2]. Furthermore, its goal is to prescribe a solution. Therefore the objectives of this pre-study were to:

- identify in what activities the students are engaging;

- identify causes for lack of engagement in their studies, if any;

- identify possible changes to the additive manufacturing course.

\section{Context}

Because part of the data analysis is qualitative, enough information must be provided about the context surrounding the pre-study for readers to assess if the findings are transferable to their own context [2]. Furtermore, because student engagement can be influenced by so many factors [3], the following background information can provide insight while interpreting results. École de technologie supérieure (ÉTS) is the largest engineering school in the province of Québec with a 7000 undergraduate student population. It offers seven (7) undergraduate engineering programs, mechanical engineering being one of the largest. It caters to a very diverse population. About $80 \%$ of students admitted to an engineering program graduated from a three year vocational training as technicians from a Québec cegep. Another 8\% have similar training obtained in another country, mostly France. In mechanical engineering, students from eighteen (18) different technical programs are admissible. The other $12 \%$ or so of students have completed the equivalent of a two-year general science cegep program and one year technical program at ÉTS before being admitted into engineering. Neither quotas nor student selection method, other than having obtained the proper collegiate diploma, are applied on admission.

All engineering programs are full coop, with students spending at least three (3), twelve (12) to sixteen (16) week paid internships in industry. On average, every graduate receives eight (8) job offers.

An important proportion of the students are first generation university students, neither of their parents having studied at university.

The additive manufacturing course is worth three (3) credits which represents a nine (9) hour per week student workload for a total of 135 hours per trimester. At ÉTS, all undergraduate three credit courses, provide five (5) hours of contact time, three (3) of which are held in a classroom and usually spent on theoretical and varying amounts of practice and two (2) hours of laboratory, problem solving or project based work. The three (3) hour classroom time is usually organized as follows: 90 minutes in class, 30 minute pause, 90 minutes in class. Students are asked to provide an additional four (4) hours of unsupervised personal or team work per week.

The course is structured around three (3) major activities:

- collaborative writing and constructive criticism of class notes on the different additive manufacturing technologies and applications;

- design and fabrication of a prototype, component or tooling;

- elaboration of a technology selection decision tool.

Detailed written instructions are provided for each activity. Furthermore, care is taken to provide an industrial context, as well as academic goals, for each activity.

About two-third (2/3) of classroom time is spent on highly interactive lectures which are intended to provide sufficient information and structure for the students to perform the activities efficiently. Two full lectures (six (6) hours) are devoted to the theoretical aspects (physics, chemistry and mechanics) of one additive manufacturing process: photopolymerisation. About one third (1/3) of laboratory time is spent learning the software to drive the additive manufacturing machines and demonstrations on how to use various equipment. The rest of classtime and laboratory time is left available so students can work on the different activities with supervision and help available.

One midterm and one final exam account for $35 \%$ of the final mark and the three activities represent $65 \%$.

The pedagogical scenario for this course differs significantly from the vast majority of courses in the program which take a much more traditional lecture/exercices/exam form. 


\section{Method}

Senior students physically attending an optional course in mechanical engineering at École de technologie supérieure were asked to anonymously react in writing to the following four statements, indicating if the statement was true or false in their case and justifying their answers using free-form text. The statements were elaborated after discussions with colleagues in the department. They represent the perception of the majority of the professors partaking in these discussions. The first three statements were worded negatively to make the students react, encouraging them to counterargument.

1. Studies are not today's students' priority.

2. Students are not here (at university) to learn but to get a diploma.

3. Students are unable to concentrate.

4. When given the opportunity, students prefer taking a class with a lecturer (rather than a professor) because they think they will obtain a better grade.

In order to identify possible solutions, students were also asked to answer the following question:

5. What form does the ideal class take for you?

The survey took place after the official class evaluation, during the $10^{\text {th }}$ class. The author explained why the survey was important and where the four statements came from.

The four statements and the question were written on the blackboard and the following instructions were given orally:

- For statements 1 to 4 , say if the statement applies to you personally (True or False) and explain.

- For question 5, simply answer the question.

The data for the pre-study was collected in the winter semester of 2014 when the course was offered in the 6 p.m. to 9 h30 p.m. time slot. Twenty-seven (27) students, of the thirty (30) registered in the course, were present in class at the moment of the survey.

Free-form text was privileged for the survey since it seemed the best way to understand the students' point of view regarding their engagement towards their studies, considering that student perspective can differ from that of the teaching staff, as is suggested by the Conseil supérieur de l'éducation du Québec (2008) [4]. Christenson, Reschly, Wiley (2012) [3] also contend that cognitive and affective engagement require understanding the student perspective and voice.

Quantitative analysis was performed by two persons by counting the number of True or False answers to the first four (4) questions. Qualitative analysis was performed on the free-form written text using the analysis grid present in appendix A. It was done twice by the author at a three months interval.

Part 1 of the qualitative analysis grid focuses on finding evidence of the different meanings of engagement as proposed by Krause (active participation in academic activities, appointment is busy schedule or combat). In part 2, student voice is captured along two axes: the nature of the engagement (positive, non- or negative) and the dimension of engagement (behavioral, emotional and cognitive). When other themes not present in the grid were voiced, they were noted.

\section{Results and discussion}

\subsection{Response to statements}

Quantitative results for the first two statements are presented in Table 1 . Out of the 27 students, 11 said that their studies was not their priority (T), 1 student was ambivalent (T/F), 4 did not say (-) and 11 students infirmed the statement, therefore saying that their studies was their priority.

A much larger number of students, twelve (12), said the they were not at university to learn but to earn a diploma (T) when compared to the three (3) students who said the contrary (F). Six (6) students were ambivalent $(\mathrm{T} / \mathrm{F})$. The qualitative analysis revealed that in these cases, they valued learning over the diploma if they found the instructor or course content interesting or pertinent to present or future work or if they found it was well taught. Six (6) students did not say.

Table 1: Results for statements 1 and 2.

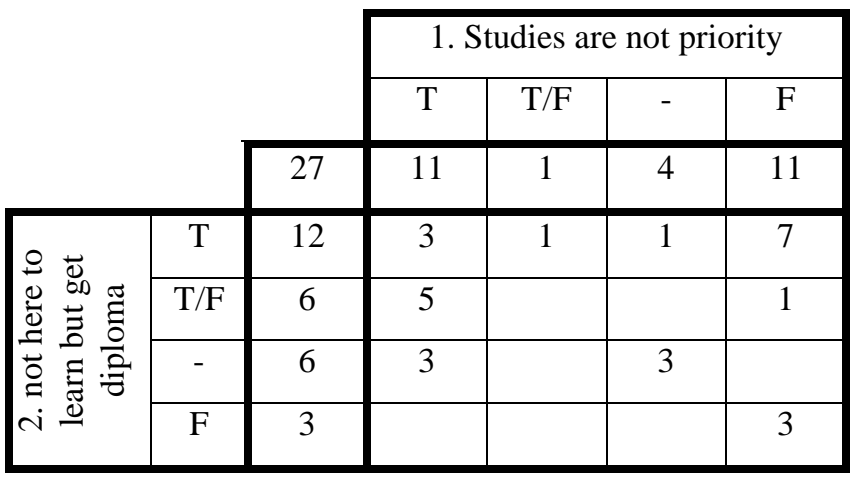

One would think that students who prioritize their studies and value learning more than obtaining a diploma would be the most engaged in their studies. Three (3) students show both these characteristics (lower right corner of Table 1). Two of them have very interesting profiles. One works 35 hours per week and is starting his own company. He says he concentrates on important points. The other is highly involved in a student scientific club. When push comes to shove, usually around club competition time, courses are unfortunately put aside if the course instructors will not make allowances. This student deplores the situation and its consequences: a lowering of grades and the fact that he cannot learn all that could be learned. 
At the opposite of the spectrum, one could believe that those students for whom studies are not a priority and who value the diploma over learning (upper left corner of Table 1) would be the least engaged. Again, three (3) students show these characteristics. In one case, there was a sense of alienation, the student having the impression of being "a pawn that enriches the school" '. For another, being very creative, having to sit and listen to lectures is proving to be a "nightmare". The other has children and works full-time to support his family. He says that he tries to put the necessary efforts to maintain good grades.

Inability to concentrate is a problem for many students, as shown in Table 2. Eighteen (18) students mentioned having difficulty concentrating, two (2) doing so depending on the conditions and two (2) mentioning having no such difficulty. Five (5) students did not say. Twenty (20) students offered explanations for this situation, many students mentioning multiple reasons. The most often cited source of distraction is the presence of electronic devices (smart phones, laptop computers, tablets) which were mentioned by twelve (12) students. Teaching methods came a close second, with ten (10) students mentioning that they lose interest during demonstrations, when the rhythm is too slow, when there is no interaction, when the instructor is not passionate... Six (6) students mentioned that they will have difficulty concentrating if the course content does not appeal to them, either because of the subject matter or if it contains too much theory.

Table 2: Results for statement 3 - Students are unable to concentrate

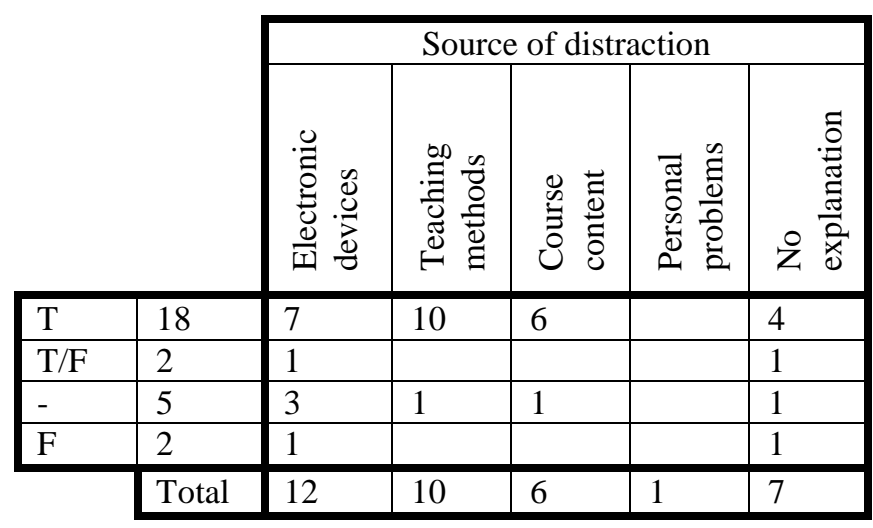

\subsection{Alternative meanings to engagement}

The answers to all statements and question were analyzed to find evidence of meanings of engagement other than active participation in academic activities as proposed by Krause: 1) appointment in a busy schedule and 3) combat.

\footnotetext{
${ }^{1}$ Excerpts were translated from French by the author.
}

Seventeen (17) students mentioned having activities that interfered with their studies, some of which having multiple other activities.

- Nine (9) students were involved in personal activities or pursuing personal pleasure/ happiness. Excerpts from four students follow: "My priority is my well-being"; "Student life is more interesting than studying. At this point in my life, I prioritize instantaneous pleasure rather than long term projects. I used to work hard, now I go out a lot.". "My goal is to obtain my diploma with good grades but by investing the minimal amount of time so that I can practice sports." "The important thing...is to try to be happy.... With the baby-boomer heritage, might as well take advantage (of our best years) now because future perspectives are rather grim."

- Nine (9) students mentioned that they spent a considerable amount of time working. One (1) student did so to support his family, two (2) in order to reimburse their debts, two (2) to prepare their future and one (1) in order to consume "like everybody else"; the others did not say.

- One (1) student mentioned being greatly involved in student clubs.

Skinner and Pitzer (2011) [10] propose four levels of engagement which can contribute in one way or another to positive youth development: prosocial institutions (such as church, family, workplace, etc.); school activities (student clubs, student governing bodies, etc.), classroom and learning activities. The majority of students engage primarily in one or more of these activities. However, an important proportion of the respondents, a third (1/3), were engaging outside this framework, pursuing personal pleasure/happiness.

It is not so surprising that only two students showed signs of studies being a form of combat, since the majority of students experiencing difficulties leave after the first three semesters. Nonetheless, the following excerpts paint a rather dark picture for those who do persevere:

"The content in most courses is good to know for an engineer but is extremely painful to learn... I have a creative personality. Sitting down and listening to a professor for three hours does not give me the opportunity to mobilize this creativity. Conventional school is a nightmare for me and $50 \%$ of the population."; "It is often discouraging to see that the reward is not worth the pain."

\subsection{Qualitative analysis highlights}

Once again, the answers to all statements and question were analyzed to find evidence of positive, nonengagement and negative engagement. 
4.3.1 Behavioral dimension The easiest form of evidence to observe and gather is behavioral, especially physical presence. Three (3) students, out of thirty (30) enrolled in the course, were absent without motivation at the moment of the survey. An additional three (3) students said that they frequently skipped class. "If the professor is interesting, I go to my classes. If the instructor just does a series of exercises, I don't go". "At the beginning of my baccalaureate, I used to go to all my courses, I had good grades, I was happy. Now I go to 2/3 of my classes, I don't study at night..." ; "Everything is accessible. Courses therefore are worth the information they offer. Personally, I go to only 25\% of my courses because I cannot concentrate in a theoretical course." The author was told on a few occasions by the students themselves that she was lucky that so many students stayed for her class, especially considering the $6 \mathrm{pm}$ to $9: 30 \mathrm{pm}$ time slot.

No manifestations of negative behavioral engagement were observed.

4.3.2 Emotional dimension The largest number of themes that emerged from the analysis were emotional in nature. The four themes that were mentioned most often are reported here.

Interest, or lack thereof, was mentioned by seventeen (17) students. It is very strongly linked to the perceived usefulness or relevance of the course content to present or future work in fifteen (15) cases and to exam material by two (2) students. "I am here to work in a field that interests me. It is more difficult to focus on a content that is less related to my interests." ; "If it is not relevant, it is normal that we don't listen". "When the course goes on and on with content that is not on the exam, we loose interest".

Frustration or anger was perceived in the answers of nine (8) students and were related to teaching and evaluation modalities. Some students expressed their outrage at being drilled. "We can easily get our diploma by repetitively solving problems. During exams, we find a problem that resembles to one we already solved and we apply the recipe. No need to think. Is this learning ?"; "I got a B+ and a A- in two physics courses by <bullshitting> the exams, without understanding a thing". "Exams are also very problematic because those who apply the <recipe> the fastest are those who get the best marks". Six (6) students questioned the weighting of evaluations. "During projects, we think; however, they are not highly valued with regards to final marks. The only A I obtained at university was in a course where the project was worth $60 \%$." ; "No 40 hour homework worth $5 \%$ of marks."; "I hate working hours on a report worth $5 \%$ when the exam lasts 3 hours and is worth 40\%." ; "For me, the most painful is to produce useless projects/reports."
Restlessness is usually considered a form of behavioral non-engagement, as it manifests itself by fidgeting, sighing out load, etc. This pre-study found evidence of what the author categorizes as emotional restlessness which she did not encounter in the literature. It is characterized by impatience to finish. Four (4) students showed signs of emotional restlessness. "My second priority is to finish my studies as fast as possible." "Where I am at now ( $3^{\text {rd }}$ year), I have the impression that the sauce is getting thin. I am ready to work." ; "I have already found a job and work 40 hours a week. At this point in time, I just want to finish my baccalaureate and get my diploma".

Some form of rejection, a manifestation of negative engagement, was present in the answers of seven (7) students. "I never have the impression that what I learn is sufficiently practical to be of real use. Of course we then think that we are there for the diploma and that we will learn the real things at work." "Everybody knows that you will learn nothing in school. It is at work that we are taught how to do. The famous sentence < Forget all you learned at school. > explains well what I want to say." ; "Indeed I am here for the diploma because it is evident that I will be trained to the image of the company".

4.3.3 Cognitive dimension Providing challenge is proposed by different authors to foster engagement as reported by Trowler [11]. Three (3) students, all of which said that their studies were their priority, had a preference for challenge "(the ideal course has) difficult but honest exams"; "exams are simply not difficult enough, which explains why the majority of students put in less effort"; "Courses that are too easy don't encourage students to be rigorous and courses that are too (sic) demanding force people to surpass themselves". On the other hand seven (7) students showed signs of non-engagement by requiring less challenge and study. "We prefer professors that are qualified but that give less work"; "But a course too heavy on theory or with a workload too large only makes me want to get my diploma as quickly as possible." ; "As long as we can get our diploma, there is no true incentive to work very hard"; "The ideal course is one that is exciting, with examples that help to understand and with little personal work."

A too heavy workload is often mentioned as a source of dissatisfaction in the official course evaluation results for the additive manufacturing course. However, in the fall of 2012, students were asked to keep a log of the time spend on unsupervised coursework, which should normally be 60 hours over the semester. The class average was of $47,1 \pm 16,5$ hours, with only six (6) students, out of a total of twenty-nine (29) spending the required amount of time or more. It is hypothesized that the workload in the majority of other courses in the program is much less and this constitutes the standard or norm against which workload is appreciated. 
No manifestations of negative cognitive engagement were observed.

\section{Changes to additive manufacturing course}

Some manifestations of non-engagement are personal to the students. What one student finds interesting and relevant might not be for another. Nonetheless, some improvements can be made to the course in which the prestudy was conducted. Finn and Zimme (2012) [6] suggest instructional approaches that require student-student interaction, in-depth inquiry and metacognition and that are authentic. Based on these recommendations and on the findings reported here, three changes are proposed, while keeping the same level of challenge and workload.

1) For a number of years, the author has had some qualms about the six (6) hour lectures on the theoretical aspects of photopolymerisation. These lectures are aimed at raising awareness on the importance of basic science to the development and optimization of the process. However, it is not required knowledge to realize either one of the three activities and it would only be beneficial to those students who would develop such a process or, to a lesser degree, operate an industrial grade photopolymerisation machine which, to the author's knowledge, has never been the case for any student having taken the course. Given the importance that students at ÉTS place on work related knowledge, the author is considering replacing these lectures with an activity on experimental parameter selection coupled with design of experiments lectures, which is much more representative of how industry deals with process parameter selection.

2) Although care is taken, within the written activity instructions, to describe the industrial context to which the three major course activities relate to, time should be spent in class to discuss and emphasize this point. Speakers from industry will also be invited more frequently to interact with the students.

3) More time will be spent in class on active learning activities such heuristic/concept mapping.

\section{Conclusion}

The goal of this pre-study was to prescribe a solution to a perceived decrease in student engagement in an elective course on additive manufacturing. .The objectives were to:

- identify in what activities the students are engaging;

- identify causes for lack of engagement in their studies, if any;

- identify possible changes to the additive manufacturing course.

A mixed (quantitative and qualitative) triangulation interpretivist approach was used to address the first two objectives. Approximately half $(1 / 2)$ the students stated that their studies was not their priority, two thirds $(2 / 3)$ reported that they attended university primarily to earn a diploma rather than to learn and again two thirds (2/3) said that they had difficulty concentrating, signs that most students are not fully engaged in learning. The qualitative analysis was done using a novel grid composed of indicators frequently associated with positive, non- and negative engagement. It provided insight and nuance to the quantitative analysis. Thanks to mixed coding, a new indicator, named emotional restlessness was identified. Qualitative analysis made possible the identification of sources for lack of engagement. Apart from the presence of electronic devices which distract attention, teaching methods, course content and evaluation modalities were often cited.

The findings were helpful in identifying three changes to the course: one is related to the content, taking out material which was difficult to relate to the major course activities and to the workplace and replacing it with more authentically work-related content; another is meant to emphasize industrial relevance of the course content while the third is meant to increase student activities during lectures.

Some of the non-engagement and negative engagement manifestations cannot be reversed in a single course and should be dealt with at the program level. This is the case with the perception of what is a "normal" workload is. A reflection should also be held at the program level on teaching methods, learning activities and evaluation modalities.

A more comprehensive study is needed to verify if there is an evolution in student engagement from the $1^{\text {st }}$ to last year, as there appears to be, if the results hold for other programs at ÉTS, for other institutions, other fields of study. Are the underlying reasons the same? This prestudy, which relied heavily on qualitative analysis to uncover the reasons for non-engagement, could be used as phase one of a two phase exploratory study, the second relying more on quantitative data, informed by phase 1 qualitative analysis, in order to speed up analysis for a larger number of respondents.

\section{Acknowledgements}

The author wishes to thank C. Pechard, Student services counsellor, for her help with data analysis.

\section{References}

[1] James J. Appleton, Sandra L. Christenson, and Michael J. Furlong, 'Student Engagement with School: Critical Conceptual and Methodological Issues of the Construct', Psychology in the Schools, 45 (2008), 369-86. 
[2] Maura Borrego, Elliot P. Douglas, and Catherine T. Amelink, 'Quantitative, Qualitative, and Mixed Research Methods in Engineering Education', Journal of Engineering Education, 98 (2009), 53-66.

[3] Sandra L. Christenson, Amy Reschly, L., and Cathy Wylie, 'Epilogue', in Handbook of Research on Student Engagement, ed. by Sandra L. Christenson, Amy Reschly, L. and Cathy Wylie (New York: Spinger Science+Business Media, 2012), pp. xxviii838.

[4] Conseil supérieur de l'éducation, 'Au collégial l'engagement de l'étudiant dans son projet de formation: une responsabilité partagée avec les acteurs de son collège. Avis à la Ministre de l'éducation, du loisir et du sport', (Québec: 2008), p. 102. Consulted December 152015. https://www.cse.gouv.qc.ca/fichiers/documents/publ ications/Avis/50-0457.pdf

[5] Aline Dresch, Daniel Pacheco Lacerda, and José Antônio Valle Antunes Jr, Design Science Research: A Method for Science and Technology Advancement (Cham (Switzerland): Springer Science+Business Media, 2014), pp. xviii-161.

[6] Jeremy D. Finn, and Kayla S. Zimmer, 'Student Engagement: What Is It? Why Does It Matter?', in Handbook of Research on Student Engagement, ed. by Sandra L. Christenson and Amy Reschly, L. New York: Springer Science+Business Media, 2012, pp. 97-132.
[7] Jennifer A. Fredricks, Phyllis C. Blumenfeld, and Alison H. Paris, 'School Engagement: Potential of the Concept, State of the Evidence', Review of Educational Research, 4 (2004), 59-109. Available at http://rer.sagepub.com/content/74/1/59.abstract

[8] Kerri-Lee Krause, Understanding and Promoting Student Engagement in University Learning Communities. University of Melbourne, Centre for the Study of Higher Education, 2005, 15 pp. Consulted November 102015 at http://melbournecshe.unimelb.edu.au/_data/assets/pdf_file/0007/176 1523/Stud_eng.pdf

[9] Jim Parsons and Leah Taylor, Student Engagement: What do we know and what should we do? University of Alberta, 2011, 59 pp. Consulted November 102015 at http:// folioz.ca/artefact/file/download.php?file $=11327 \&$ vie $\mathrm{w}=130$.

[10] Ellen A. Skinner and Jennifer R. Pizter. "Developmental Dynamics of Student Engagement, Coping and Everyday Resilience" in in Handbook of Research on Student Engagement, ed. by Sandra L. Christenson and Amy Reschly, L. New York: Springer Science+Business Media, 2012, pp. 21-44.

[11] Vicky Trowler, Student Engagement Literature Review. Heslington (York): The Higher Education Academy, 2010, 70 pp. Consulted November 10 2015 from https://www.heacademy.ac.uk/sites/default/files/stud entengagementliteraturereview_1.pdf 


\section{APPENDIX A: Analysis grid}

Student number :

\begin{tabular}{|l|l|l|l|}
\hline Q1: studies not priority & Q2 diploma over learning & $\begin{array}{l}\text { Q3: difficulty } \\
\text { concentration }\end{array}$ & $\begin{array}{l}\text { Q4-prefer sessional } \\
\text { lecturer - higher grades }\end{array}$ \\
\hline & & & \\
\hline
\end{tabular}

Part 1; Meaning of engagement (Krause) Academic

Schedule other pursuits: Work

Family

Student clubs

Student governance

Sports

Personal pleasure

Combat

Other

Part 2: positive, non-engagement, negative engagement

\begin{tabular}{|c|c|c|c|}
\hline & Positive engagement & Non-engagement & Negative engagement \\
\hline Bebavioral & $\begin{array}{l}\text { present } \\
\text { Action initiation } \\
\text { Effert, exertion } \\
\text { Working hard } \\
\text { Attemps } \\
\text { Persistence } \\
\text { Focus, attention, } \\
\text { concentration } \\
\text { Absorption } \\
\text { Involyment } \\
\text { Self-regulation }\end{array}$ & $\begin{array}{l}\text { Absent without cause } \\
\text { Passitivity } \\
\text { procrastination } \\
\text { Giving up } \\
\text { Restlessness } \\
\text { Half-hearted } \\
\text { Unfocused, inattentive, } \\
\text { lack concentration } \\
\text { Distracted } \\
\text { Mentally withdrawn } \\
\text { Burned.exhausted } \\
\text { Unprepared } \\
\text { Lack of self-regulation } \\
\text { Minimal effort }\end{array}$ & $\begin{array}{l}\text { Boycotts, pickets or } \\
\quad \text { disrupts lectures or } \\
\quad \text { other class activities } \\
\text { Rude } \\
\text { Disrespectful }\end{array}$ \\
\hline Emotional & $\begin{array}{l}\text { Entbusiams } \\
\text { Interest } \\
\text { Enjoyment } \\
\text { Satisfaction } \\
\text { Pride } \\
\text { Vitality } \\
\text { zest }\end{array}$ & $\begin{array}{l}\text { Boredom } \\
\text { Disinterest } \\
\text { Frustration/anger } \\
\text { Sadness } \\
\text { Worry/anxiety } \\
\text { Shame } \\
\text { Self-blame }\end{array}$ & Rejection \\
\hline Cognitive & $\begin{array}{l}\text { Purposeful } \\
\text { Approach } \\
\text { Goal striving } \\
\text { Strategy search } \\
\text { Willing participation } \\
\text { Preference for challenge } \\
\text { Mastery } \\
\text { Follow-through, care } \\
\text { thoroughness }\end{array}$ & $\begin{array}{l}\text { Aimless } \\
\text { Helpless, hopeless } \\
\text { Resigned } \\
\text { Unwilling } \\
\text { Avoidance } \\
\text { Apathy } \\
\text { pressured }\end{array}$ & $\begin{array}{l}\text { Opposition } \\
\text { Redefines parameters for } \\
\text { assignments }\end{array}$ \\
\hline
\end{tabular}

CEEA16; Paper 9 